\title{
Data Validation and Case Studies using the TET-1 Thermal Infrared Satellite System
}

\author{
C. Fischer ${ }^{a *}$, D. Klein ${ }^{\text {a }}$, G. Kerr ${ }^{\text {a }}$, E. Stein ${ }^{\text {a }}$, E. Lorenz ${ }^{\text {, }}$ O. Frauenberger ${ }^{\text {a }}$, E. Borg \\ ${ }^{a}$ German Aerospace Center, German Remote Sensing Data Center - (c.fischer, doris.klein, gregoire.kerr, enrico.stein, \\ olaf.frauenberger, erik.borg)@dlr.de \\ ${ }^{\mathrm{b}}$ German Aerospace Center, Institute for Optical Sensor Systems - eckehard.lorenz@dlr.de
}

\begin{abstract}
KEY WORDS: Thermal Infrared Remote Sensing, High temperature Event, Fire Radiative Power, TET-1, FireBird
\end{abstract}
\begin{abstract}
:
Based on the DLR satellite system BIRD, launched and operated in the early 2000, the TET-1 satellite has been launched in 2012 as part of the FireBird satellite constellation. The constellation will consist of two satellites, the second one to be launched in the first half of 2016. Acquired imagery is processed and archived by DLR and will be publicly available. For this purpose, a processing chain has been implemented converting raw data (level 0 product) to geo-annotated at-sensor radiance (level 1b). Further data products can be derived, e.g. information on brightness temperature, fire radiative power, and surface emissivity. Other processing levels, such as atmospherically corrected reflectance, could also be produced. The sensitivity of a Thermal Infrared (TIR) sensor system depends on its spectral characteristics and its spatial resolution. Various methods for high temperature event (HTE) detection and quantification have been developed, which can be categorized into single- and multi-band algorithms. While single band methods rely on the robust demarcation of background pixels and higher temperature pixels, considered as being anomalous, the TET-1 system facilitates the application of the widely used bi-spectral algorithm approach introduced by Dozier (1981), using the mid-infrared and longwave-infrared channel. This approach takes advantage of the non-linear nature of the Planck's curves to calculate temperatures and the HTE area on a sub-pixel basis. TIR remote sensing can make a significant contribution to the detection and, partly, the monitoring of land surface temperature (LST), HTE and of parameters describing the surface energy balance for specific areas.
\end{abstract}

\section{INTRODUCTION}

Thermal infrared remote sensing is an important source of information on the status of land cover and water bodies and thus enables the detection and monitoring of specific high temperature events (HTE) with distinct thermal characteristic different to their surroundings. For civil security monitoring of volcanoes and fires is an important issue. Further fire detection and characterization is relevant in the context of climate change and global change analysis. Vegetation, peat land or coal fires cause severe environmental problems, can be hazardous to humans and their emissions play an important role in climatological studies.

Besides detection, mapping, and quantification of high temperature events based on TIR data are important to describe biophysical and hydrologic interactions of land surface processes. This includes processes across land surface patterns as well as between land surface and atmosphere. This includes processes across land surface patterns as well as between land surface and atmosphere. Künzer and Dech (2013) state that measurement of land surface temperatures (LST) related to individual landscapes and their biophysical components and secondly the relations of LST with energy fluxes are fundamental reasons why TIR data contribute to an improved understanding of and surface processes.

Consequently, it is crucial to have access to reliable estimates of thermal behaviour over large areas, covering different spatial and temporal scales. Further investigations have to address the development of numeric models, which will help to describe the energy balance terms of topographic surface and its different land-cover classes. In this paper the main scientific background for thermal remote sensing will be presented as well as examples of the thermal infrared data of DLR's FireBird mission and their potential use.

\subsection{Thermal Remote Sensing}

Thermal-Infrared remote sensing exploits the individual radiation emitted by different land-cover types. The thermal signature of an object is mainly controlled by its emissivity, its temperature and, to a certain extent, its geometry. For an idealised perfect emitter, a so called blackbody, the Planck's law relates spectral radiance to the kinetic temperature $\mathrm{T}[\mathrm{K}]$ and wavelength $\lambda[\mathrm{m}]$ with

$$
L_{B B}(\lambda, T)=\frac{2 h c^{2}}{\lambda^{5}}\left(\frac{1}{e^{\frac{h c}{\lambda k T}}-1}\right)
$$

Where $L_{B B}\left[\frac{W}{s r m^{2} m}\right]$ is the spectral radiance of a perfect emitter, $\mathrm{h}[\mathrm{Js}]$ is the Plancks's constant, $\mathrm{k}\left[\frac{J}{K}\right]$ the Boltzmann's constant and $\mathrm{c}\left[\frac{\mathrm{m}}{\mathrm{s}}\right]$ the speed of the light in vacuum. For passive optical sensors focusing on terrestrial applications two sources of electromagnetic radiation are of relevance. The Sun illuminates the Earth with an intensity spectrum being approximately the one of a blackbody at a temperature of $6000 \mathrm{~K}$ when neglecting effects induced by the solar atmosphere. The Earth's surface itself also emits electromagnetic radiation which intensity spectrum can be approximated by a blackbody of its respective temperature, i.e. $300 \mathrm{~K}$. According to Wien's displacement law, solar radiation reflected by the Earth's surface reaches its maximum intensity for the visible wavelengths $(0.480 \mu \mathrm{m})$ while the typical surface

* Corresponding author 
emitted radiation peaks in the thermal domain $(9.7 \mu \mathrm{m})$. Hence reflective and emissive spectral domain can be used to independently derive complementary surface information. For the thermal domain (TIR) the basic radiative transfer equitation (2) is given as

$$
L_{a s}^{e}(\lambda)=L_{\text {path }}^{e}(\lambda)+\tau^{e}(\lambda) * L_{a g}^{e}(\lambda)+\tau^{e}(\lambda) *[1-\varepsilon(\lambda)] * \frac{F^{e}(\lambda)}{\pi}
$$

Whereas $L_{a s}^{e}(\lambda)$ describes the total thermal radiance at sensor, $L_{\text {path }}^{e}(\lambda)$ the thermal path radiance emitted by the atmospheric layer between ground and sensor, $\tau^{e}(\lambda)$ the ground-to-sensor atmospheric thermal transmittance, $L_{a g}^{e}(\lambda)$ the ground emitted radiance, $\varepsilon(\lambda)$ the ground surface emissivity and $F^{e}(\lambda)$ the down-welling thermal sky flux at the ground (Richter, Coll, 2002).

During day-time, the mid-infrared spectral range (MIR, 3-5 $\mu \mathrm{m}$ ) the path radiance consists of a reflective and an emitted thermal part, whereas the long-wave infrared (LWIR, 9-12 $\mu \mathrm{m}$ ) part is based on emittance only. During night-time, in both wavelength domains only the thermal component is of importance, influenced by the emitted radiance of different air layers between the ground and the sensor, influencing the total atsensor signal. In addition, surface scattering reflects a part of the incident radiation. Part of the incident radiation is transmitted into the ground, where it is absorbed while another part may exit into the ground. The absorbed radiation leads to an increase of the kinetic temperature of the ground, which promotes the emission of electromagnetic radiation in the thermal domain (TIR) which a sensor operating in the relevant spectral region can detect. Thus, Land-Surface-Temperature (LST) results by the interaction of incident electromagnetic radiation with the ground surface, which is governed by reflection, transmission and absorption processes.

\subsection{High-temperature Events (HTE)}

LST is mostly maintained by the incoming solar radiation and longwave irradiation, including sensible and latent heat fluxes at the surface and shows a rather homogeneous pattern depending on land cover. Evident thermal anomalies, as burning vegetation, coal fires, volcanoes, natural and man-made hazards emit significant higher thermal energy with respect to the nominal background temperature. Infrared spectroradiometers can be used directly to measure the radiative energy released by a high-temperature-event (HTE). Nevertheless, it is important to note, that satellite sensors can only register that part of the total fire energy emission that is released as radiation, when taking fire and background temperatures in the MWIR and LWIR into account. When observing locations with high temperatures and the existing background temperatures, the radiative energy release $M_{\text {FIRE }}$ [W] of the pixel-related fire component can be calculated as follows (Dozier, 1981):

$M_{\text {FIRE }}=A_{\text {pixel }} * \sigma^{*} \varepsilon_{\text {FIRE }} \sum q_{f n} * T_{f n}^{4}$

Where $A_{\text {pixel }}$ describes the ground sampling area $\left[\mathrm{m}^{2}\right], \sigma$ is the Stefan-Boltzmann constant $\left[\mathrm{Wm}^{-2} \mathrm{~K}^{-4}\right], e_{f}$ is the fire emissivity and $q_{f n}$ the nth thermal component with the ground pixel. Finally $T_{f n}$ is the fire thermal component [K]. Besides the detection and the spatial distribution of HTE, this approach allows the determination of fire characteristics, as it enables retrieval of temperature and area of a hot subpixel target within an otherwise uniform pixel.

\section{FIREBIRD: DLR'S THERMAL INFRARED MISSION}

The German Aerospace Center (DLR) Bispectral and Infrared Remote Detection (BIRD) small satellite was a technology demonstrating mission of new infrared pushbroom channels, specifically designed to support the detection and quantification of HTE on the Earth's surface. BIRD was developed at the Optical Information Systems department of the Institute of Robotics and Mechatronics in Berlin and was launched into a Sun-synchronous orbit in October 2001 (Briess et. al., 2003). The satellite carried two imaging instruments, the Hot Spot Recognition System (HSRS) and Wide-Angle-OptoelectronicStereo-Scanner (WAOSS-B). The HSRS had two wellseparated thermal channels: a mid-infrared band (MIR), centred at $3.8 \mu \mathrm{m}$ and a long-wave infrared band, centred at $8.9 \mu \mathrm{m}$. The WAOSS-B instrument was made of a nadir-looking, nearinfrared (NIR) band, centred at $0.87 \mu \mathrm{m}$ and two off-nadir channels, centred at $0.635 \mu \mathrm{m}$ (red) and 0.87 (NIR) $\mu \mathrm{m}$ respectively. The BIRD technology experiment demonstrated the advantages and limits of using developed and tailored components, methods and algorithms. Comprehensive results using BIRD imagery for detecting and mapping burning vegetation and coal fires can be found in (Lorenz, et. al. 2001), (Tetzlaff, 2004), (Wooster, et. al. 2003) (Künzer 2013) and (Zhukov, et. al. 2004)

\subsection{FireBird}

Based on the successful BIRD demonstrator mission ended in in 2004, DLR is continuing its activities on satellite based mapping of HTE. Thus, it currently operates the FireBird mission, which consists of the two satellites TET-1 (Technology Experiment Carrier-1), launched in July 2012 and BIROS (Berlin Infrared Optical System) scheduled for the first half of 2016. The mission is dedicated to the scientific investigation of thermal anomalies, as well as to early fire detection from space. Both satellites, TET-1 and BIROS, are based on the technological experience gained by DLR during the BIRD mission. As for BIRD, the heart of the TET- 1 and BIROS payloads is a bi-spectral infrared sensor which records signals in the mid-infrared and thermal spectral ranges (3.4-4.2 $\mu \mathrm{m}$ and 8.5-9.3 $\mu \mathrm{m})$. Another camera records the visible and near-infrared ranges in three channels. Technical details of both cameras are given in Table 1.

The push broom sensor system with thermal bands provides a ground sampling distance (GSD) of $160 \mathrm{~m}$, which is corresponding to a pixel resolution of $320 \mathrm{~m}$ due to staggering. In addition, three optical bands (green, red and near infrared) have a resolution of $40 \mathrm{~m}$ at best, but can be scaled through $4 \times 4$ binning on-board to $156 \mathrm{~m}$. The swath is $162 \mathrm{~km}$ wide for the thermal bands and $202 \mathrm{~km}$ for the optical bands, while the length of the data take is variable. Different imaging modes are available which implies different band combinations and different spatial resolutions. The revisit time for one satellite is maximum 5 days at latitude of $40^{\circ}$ north. However due to the satellites capacity of an off-nadir tilt up to $30^{\circ}$ a target might also be acquired on two consecutive days depending on 
location. When both satellites would be operational, a target can be revisited within 3.5 days.

\begin{tabular}{|c|c|c|}
\hline & Infrared-Camera & VIS-Camera \\
\hline \multirow[t]{3}{*}{ wavelength $[\mu \mathrm{m}]$} & $3.4-4.2$ & $0.46-0.56$ \\
\hline & $8.5-9.3$ & $0.56-0.72$ \\
\hline & & $0.79-0.93$ \\
\hline $\begin{array}{l}\text { ground sampling } \\
\text { distance }[\mathrm{m}]\end{array}$ & 160 & 40 \\
\hline pixel per line & $2 \times 512$ (staggered) & $1250 / 2500^{*}$ \\
\hline swath with $[\mathrm{km}]$ & 162 & 192 \\
\hline $\begin{array}{l}\text { radiometric } \\
\text { resolution [bit] }\end{array}$ & 14 & 14 \\
\hline $\begin{array}{c}\text { (rel.) accuracy } \\
{[\mathrm{m}]}\end{array}$ & $150-300$ & tbd. \\
\hline
\end{tabular}

Table 1: TET-1 / BIROS camera parameter

Land surface physical variables to be derived from FireBird data include HTE location, Fire Radiative Power (FRP) and, in case of vegetation fires, the fire length and fire line length.

\subsection{Data Processing}

The data processing levels are defined according to ESA standards. Receiving the raw data, an operational processing unit generates a standard format for the raw data. This L0 data set includes - depending on the operation mode - up to 5 measurement files, two calibration files for the infrared cameras and one attitude file. After reception, an automatic data processing chain starts generating Level $1 \mathrm{~b}$ standard products. L1b products are radiometric calibrated radiances top of atmosphere with geographic annotation and related metadata information. This information is delivered in a HDF-EOS-5 format. Based on these products L2 products will be processed, including the above mentioned HTE related information. Metainformation also includes indicators for data quality assessment.

\subsection{Data Access and Data Policy}

FireBird is a scientific mission. Thus, the main scope is to foster scientific research and development for a future operational use of TIR data for different applications. To achieve this, the data policy for FireBird will be 'free and open'. Firebird Data will be archived and delivered through the EOWEB catalogue of the German Remote Sensing Data Center (DFD).

\section{DATA VALIDATION}

First investigations have been done by correlating TET-1 daytime images with measured temperatures of a controlled fire site on ground (cp. Figure 1). This test was done on $17^{\text {th }}$ August 2013 in the calibration and validation test site DEMMIN ${ }^{\circledR 1}$,

(Borg, et. al. 2009). Based on fire radiative energy simulations, the fire site was set to a site of approximatively $150 \mathrm{~m}^{2}$. Measured fire temperatures were $\sim 900 \mathrm{~K}$, whereas the background temperature was about $\sim 300 \mathrm{~K}$.

1 (DEMMIN - Durable Environmental Multidisciplinary Monitoring Information Network is a registered trade mark of DLR)

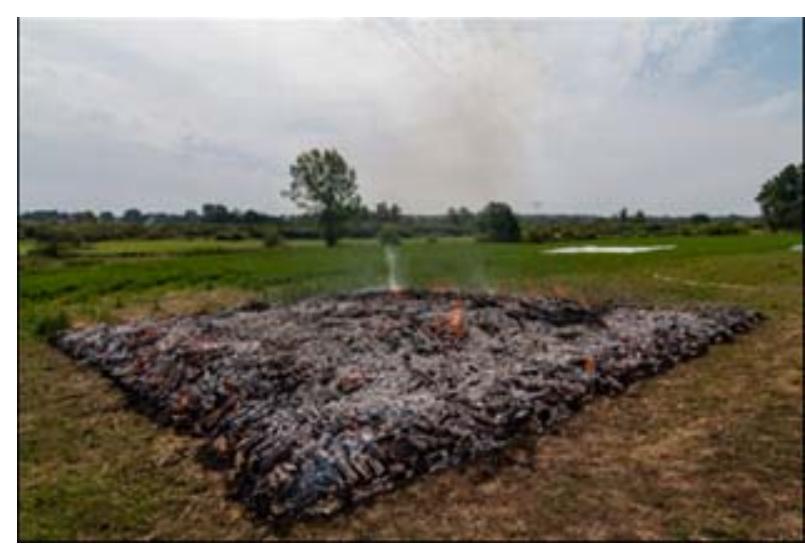

Figure 1. Test fire in the DEMMIN area


Figure 2: Overview of the DEMMIN (top row). Zoom on the test fire in the lower row. Left: Landsat 8 RGB: bands 7,6,9. Middle: L-8 RGB: band 4,3,1. Right: TET-1 MWIR band.

The results show the ability to detect comparable small fires (Figure 2). Image based fire radiative power resulted in 2.240 MW (vs. calculated 1.36 MW), which seems feasible, as no detailed atmospheric correction of the images has been applied.

\section{FIRST CASE STUDIES}

Since the beginning of the TET-1 operational phase in 2014 about 1200 data takes have been acquired. Some have covered HTE, like vegetation fires and volcanic activities. In order to evaluate the data, TET-1 data were tasked for internal use in the context of the International Charter Space \& Major Disaster (https://www.disasterscharter.org/web/guest/home)

\subsection{Wild fires in Australia}

In October 2013 almost 100 wildfires raged across New South Wales in Australia. Within the corresponding Charter Call (https://www.disasterscharter.org/web/guest/-/fires-in-austral1), TET-1 images were tasked. The acquired image (Figure 3) shows the fire fronts with the corresponding FRP in the Blue Mountains. Several fire fronts with FRP from 400 to $1600 \mathrm{MW}$ were recorded. The fires were fuelled through high fuel load (mainly pines and eucalypts), warm, dry and windy weather conditions. The September 2013 was the warmest recorded one for this region. 


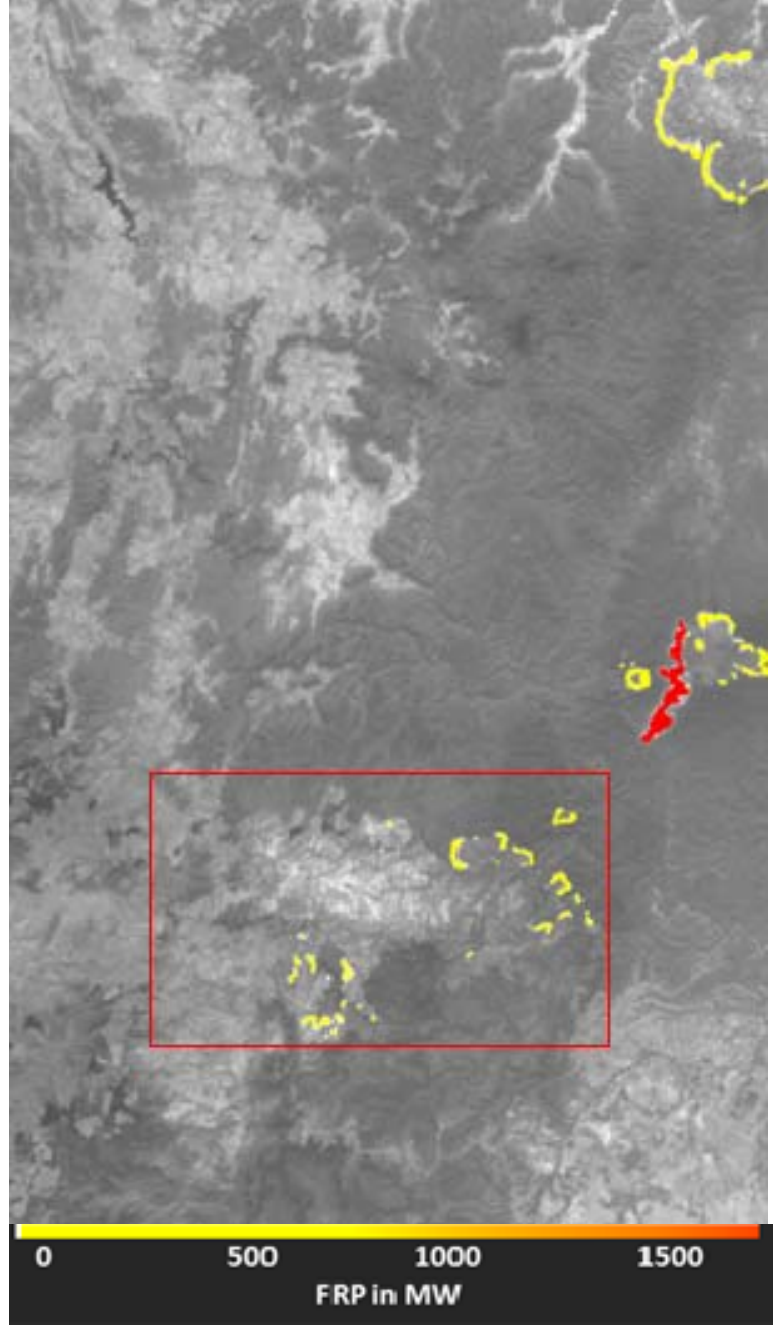

Figure 3: Calculated FRP from TET-1 image (26th Oct. 2013)

Figure 3 shows TET-1 MWIR band and detected fire fronts with corresponding amount of Fire Radiative Power (FRP)

\subsection{Wild fires in the Dominican Republic 2014}

A wildfire broke out in the La Vega Province of the Dominican Republic on 20th of July in2014. The fire was located in Valle Nuevo National Park, near Constanza, which is situated in the Cordillera Central Mountains. TET-1 data were used to estimate the burnt area using the NIR/RED bands with a semi-automated threshold based algorithm (Stein, et. al. 2011). In Figure 4 the derived burnt scar is presented, over 4,000 hectares of trees and efforts have been burnt down. The mountainous terrain complicated an effective firefighting. The United States deployed one aircraft to quench the blames.

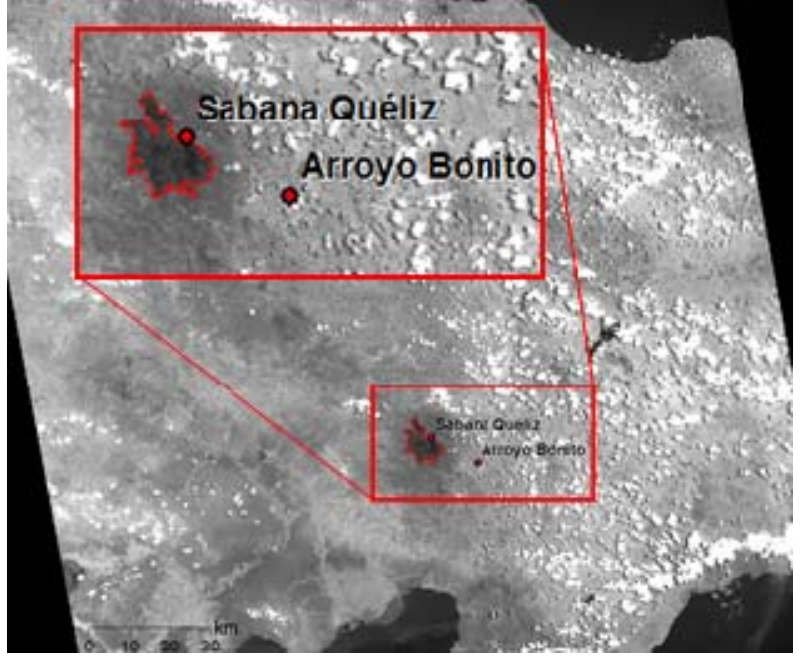

Figure 4: Overview and zoom of mapped burnt area in the Dominican Republic 2014 overlaid on the TET-1 NIR band.

\subsection{Eruption of the Villarrica in Chile}

Villarrica is one of Chile's most active volcanoes and had been showing signs of activity since beginning of February 2015. The volcano finally erupted on 3 March 2015, sending ash and lava up into the sky in a display which was reportedly seen as far as $100 \mathrm{~km}$ away. As a consequence, thousands of residents in the area have been evacuated for their safety during that time. One week before eruption took place, TET-1 recorded the HTE with the following physical variables:

\begin{tabular}{|c|c|c|c|c|}
\hline $\begin{array}{c}\text { FRP } \\
{[\mathbf{M W}]}\end{array}$ & $\begin{array}{c}\text { Tmin } \\
{[\mathbf{K}]}\end{array}$ & $\mathbf{T}[\mathbf{K}]$ & $\begin{array}{c}\text { Tmax } \\
{[\mathbf{K}]}\end{array}$ & area $\left[\mathbf{m}^{2}\right]$ \\
\hline 40,69 & 513,70 & 543,63 & 587,43 & 8216,04 \\
\hline
\end{tabular}

Table 2: TET derived HTE parameters for Villarrica.

The following Figure 5 shows the TET-1 MWIR band and the derived amount of FRP.

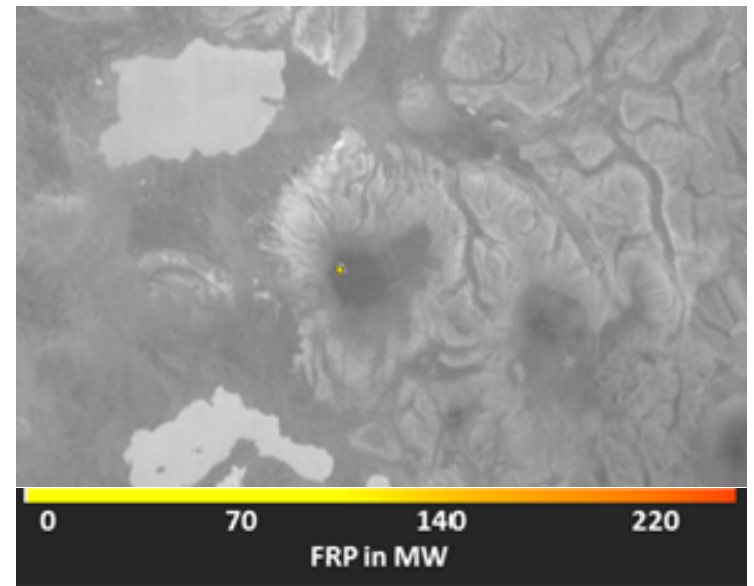

Figure 4: Calculated FRP from TET-1 image (22nd Feb. 2014) 


\subsection{Fire Experiment in Dry Savannah in Krueger National Park}

In the Kruger National Park in South Africa a long term fire experiment is conducted in order to monitor the influence of wildfires on vegetation. In this context sample plots of about $360 \mathrm{~m} \times 180 \mathrm{~m}$ size have been burned. In August 2014 this fires where scheduled to coincide with satellite overpass of MODIS, VIIRS and TET-1. The experiment included ground based measurements of fire temperature estimations of biomass, and helicopter based monitoring of radiation). The aim of the experiment is to establish a relationship between the radiative energy observed by remote sensing and the biomass consumption (Govender, et al. 2014)

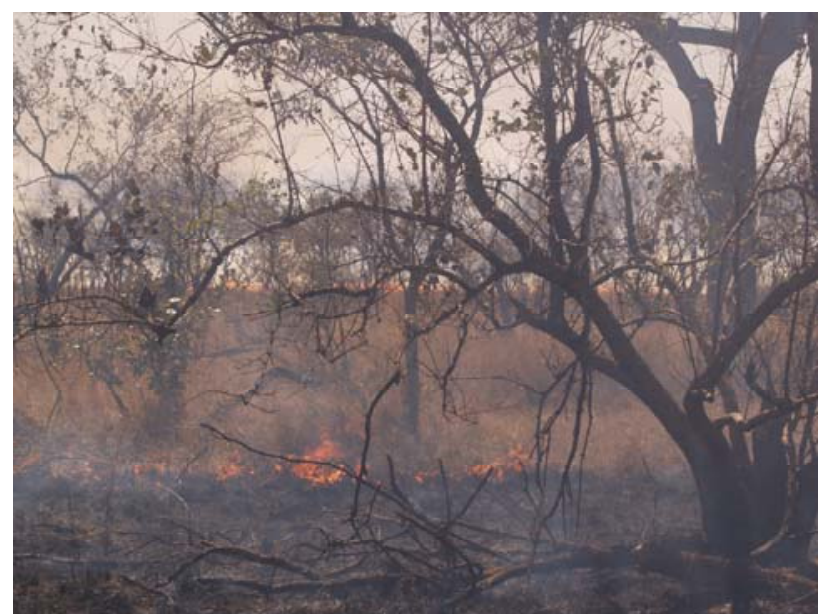

Figure 5: Burning grassland sample plot during the overpass of TET-1

Typically almost rectangular plots where lit in a way, aiming in a comparable large area, which is affected by fire with respect to the fire intensity and the size of the active fire front. As a result the fire covers approx. 17 pixels in the TET-MWIR channel. In Figure 5 both fire fronts are visible with the back fire in front. A comparison between the helicopter based measurements and the parameter retrieved from the satellite image is provided in Table 2 below (Frauenberger, et. al. 2015).

\begin{tabular}{|c|c|c|c|}
\hline & \multicolumn{3}{|c|}{ Savannah Skukuza } \\
\hline & TET & Helicopter & ratio \\
\hline $\mathrm{T}_{\text {mean }}[\mathrm{K}]$ & 580 & 595 & 0,97 \\
\hline $\mathrm{A}_{\mathrm{F}}[\mathrm{ha}]$ & 0,4722 & 0,5965 & 0,79 \\
\hline FRP $[\mathrm{MW}]$ & 30,3 & 25,5 & 1,19 \\
\hline
\end{tabular}

Table 3: HTE parameters, derived from a TET-1 scene compared to helicopter based parameter estimation).

Since active wild fires cover only a very tiny slot in time, it is difficult to observe such fires during a satellite overpass. Therefore also the estimation of burned areas is essential to come to an estimate of burned biomass. Due to their low albedo burned areas are clearly visible in the Near Infrared channel as shown in the lower section of Figure 6 while the brightness temperature is increased due to heating in the sun light in combination with a higher emission coefficient of the surface.

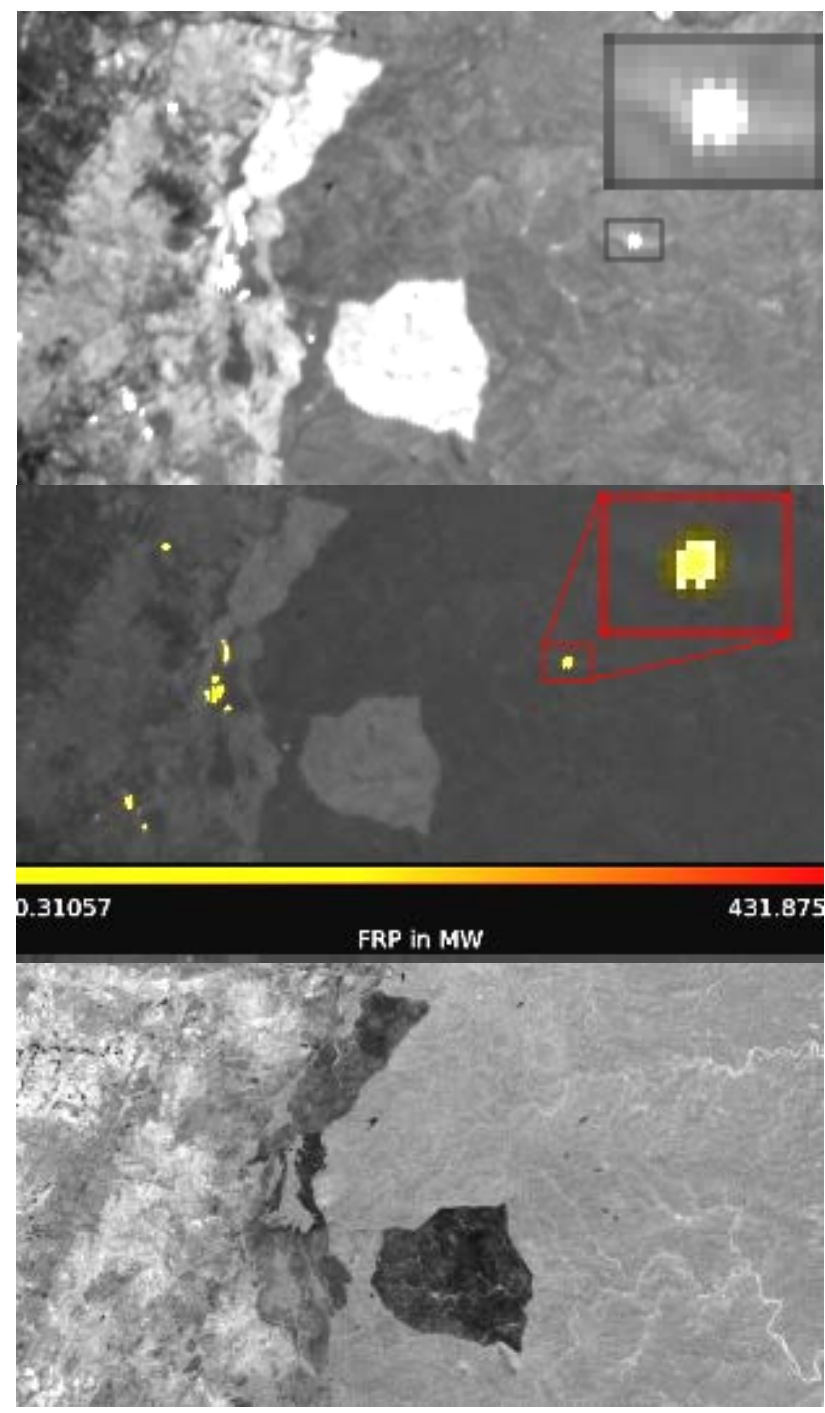

Figure 6: Fire experiment in open savannah in Kruger National Park, Republic of South Africa (26th Aug. 2014). Top: MWIR channel, Middle: FRP; Bottom NIR channel

Clearly visible in the right part of Figure 6 is the area of the Kruger National Park as a relative homogeneous area. Outside the national park are a number of additional fires visible on farm land and used for pasture in order to burn old dry vegetation (Figure 6, middle). Such man made fires occur in large numbers in the southern part of Africa causing often, when out of control, a thread to humans and properties.

\subsection{Monitoring Sea Surface Temperatures}

Although monitoring of water surfaces is not the designed task of TET-1, a good example of different water temperatures is shown in Figure 7. The dark areas indicate upwelling cold water in the Baltic Sea between Germany and Denmark. Brightness temperatures might be also used to detect maritime pollution, e. g. oil spills since they affect the emissivity of the surface in the thermal infrared range. 


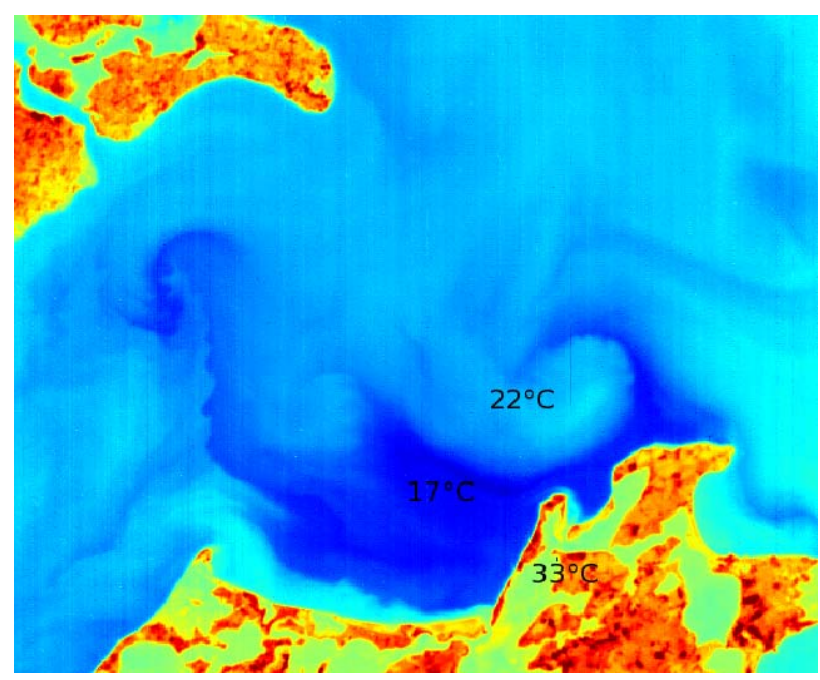

Figure 7: Sea surface temperatures on the Southern Baltic Sea, (10th July 2014)

\section{CONCLUSION AND OUTLOOK}

Current thermal remote sensing sensors have either a high temporal resolution up to $15 \mathrm{~min}$ like Meteosat Seviri or four times a day like MODIS but a low spatial resolution with $1 \mathrm{~km}$. Also the upcoming Sentinel 3 SLSTR will operate in a similar range like the MODIS sensor system. At the other hand TIRS on Landsat Data Continuity Mission (LDCM) has a higher spatial resolution but with 16 days the repetitions rate a lower temporal resolution.

The scientific FireBird mission designed to detect HTE closes a gap in between these different sensor systems with its GSD of $160 \mathrm{~m}$ for thermal data and a repetition rate of less than 5 days, once both sensors are operational. First validations have shown its potential for HTE detection and mapping. Further quantitative validation of the data in comparison to other thermal sensors has to be conducted.

\section{ACKNOWLEDGEMENTS}

The authors warmly thank the Calibration and Validation team from DLR Neustrelitz for their great support during the field campaign in summer 2013.

The authors warmly acknowledge the contributions to discussions and of data for fire energy release and temperature estimations from Martin Wooster and Roonan Paugam from the Kings College of London, UK.

Our special thanks go to Navashni Govender for organizing the validation campaign in Kruger National Park in August 2014. Relevant information has been compiled by Navashni Govender with contributions from Wilfrid Schroeder, Louis Giglio, Bob Kremans, Gernot Ruecker, Olaf Frauenberger, Martin Wooster, Mark Dejong, Bruce Main, Ronan Paugam, Evan Ellicott and Anja Hoffmann.

\section{REFERENCES}

Borg, E., Lippert, K., Zabel, E., Loepmeier, F.J., Fichtelmann, B., Jahncke, D., Maass, H., 2009. Calibration and Validation Test Site DEMMIN (http://demminweb.dlr.de/).

Briess, K., Jahn, H., Lorenz, E., Oertel, D., Skrebek, W., Zhukov, B., 2003. Fire recognition potential of the Bi-spectral InfraRed Detection (BIRD) satellite. International Journal of Remote Sensing, 24, pp. 865-872.

Dozier, J., 1981. A method for satellite identification of surface temperature fields of subpixel resolution. Remote Sensing of Environment, vol, 11, pp. 221-229.

Frauenberger, O., Börner, A., Borg, E., Halle, W., Lorenz, E., Mitchell, S., Paproth, C., Säuberlich, T., Terzibaschian, T., Wohlfeil, J. 2015. Results on verification and validation of OOV-TET1 multispectral camera observations within the FireBird project. 10th IAA Symposium on Small Satellites for Earth Observation. Berlin Germany 2015 (in press).

Govender, N., Schroeder, W., Louis Giglio, L., Kremans, B., Ruecker, G., Frauenberger, O., Wooster, M., Dejong, M., Main, B., Paugam, R., Ellicott, E., Hoffmann, A., 2014. Validation of satellite active fire data sets using coincident prescribed fire opportunities in Kruger National Park, 17th-31st August 2014. Skukuza, Kruger National Park, South Africa 2014.

Kuenzer, C., Dech, S., 2013 (Ed.). Thermal Infrared Remote Sensing: Sensors, Methods, Applications (Remote Sensing and Digital Image Processing). Springer.

Lorenz, E., Skrbek, W., 2001. Calibration of a bi-spectral infrared push-broom imager. Proceedings SPIE, vol. 4486, pp. 90-103.

Richter, R., Coll, C., 2002. Bandpass-resampling effects for the retrieval of surface emissivity. Applied Optics, 41(18), pp. 3523-3529.

Stein, E., Bernhard, E. M., Strobl, C. Strunz, G., 2011. Operational use of remote sensing on forest fires in Europe: Real-time processing and post disaster information management. In Proceedings of the 8th International EARSel Workshop: Advances in Remote Sensing and GIS applications in Forest Fire Management. From local to global assessment, Stresa, Italy. 2011.

Tetzlaff, A., 2004. Coal fire quantification using ASTER, ETM and BIRD satellite instrument data. Dissertation, LMU Munich.

Wooster, M., Zhukov, B., Oertel, D., 2003. Fire radiative energy release for quantitative study of biomass burning: Derivation from BIRD experimental satellite and comparison to MODIS fire products, Remote Sensing of Environment, vol. 86, pp. 83-107.

Zhukov, B., Lorenz, E., Oertel, D., 2004.. Experiences of detection and quantitative characterization of fires during the experimental small satellite mission BIRD. DLR-FB 2005-04, 96 p. ISSN 1434-8454. 